\title{
Craniosynostosis, Herrmann-Opitz type
}

INSERM

\section{Source}

INSERM. (1999). Orphanet: an online rare disease and orphan drug data base.

Craniosynostosis, Herrmann-Opitz type. ORPHA:2145

Craniosynostosis, Herrmann-Opitz type is a rare bone development disorder characterized by intellectual disability, short stature, turribrachycephaly, facial dysmorphism (i.e. severe hypertelorism, hypoplasia of supraorbital ridges, abnormal ears, and micrognathia), bony defects of the occiput, and dig ital anomalies (incl. syndactyly, oligodactyly, and/or brachydactyly). Urethral atresia has also been reported. There have been no further descriptions in the literature since 1987. 